Published:

Louis Caruana, 'Beyond the Internal Realist's Conceptual Scheme', Metaphilosophy 27 (1996), pp. 296-301.

\title{
BEYOND THE INTERNAL REALIST'S CONCEPTUAL SCHEME
}

\author{
LOUIS CARUANA
}

Some of Hilary Putnam's recent writings show that he has chosen to abandon metaphysical realism in favour of internal realism. This move obliges him to employ the notion of conceptual scheme, whose role is to explain how we inevitably find ourselves having one particular point of view among possible others. To ensure the possibility of agreement between all inquirers for some basic issues, is Putnam committed to having just one conceptual scheme for all human inquirers? I will argue that the answer is no, on condition that all inquirers are assumed to have some kind of common cognitive faculty.

To prepare the ground, I will start by highlighting what seems to me the three characteristics of Putnam's internal realism most relevant here.

(1) First of all, internal realists like Putnam do not commit themselves to the existence of a mind-independent reality. This is in direct opposition to the view of metaphysical realists who claim that the world exists independently of any observer, and that there is one description of the world which is the description of the world as it is 'in itself': language users only write down an imperfect version of the final description waiting to be written down. Putnam denies this. He wants to safeguard the common-sense role of the word 'true' without a commitment to mind-independent reality. In fact, he goes to great pains to show that such a commitment will lead to contradictions (Putnam 1978, 123-38; Putnam 1983, 1-25; Putnam 1981, 22-48).

(2) To explain why some judgements are true and others false, the internal realists cannot resort to correspondence to the mind-independent world but must 
accept some kind of verificationist semantics. Putnam does not use undiluted and naive verificationism. His is an idealised verificationism where the truth of a statement will be determined by its verifiability under ideal conditions and in the long run. In his own words: 'my position entails that "Lizzie Borden murdered her parents with an axe" has truth-value regardless of whether evidence that exists now or that will exist in the future will ever enable anyone to verify that Miss Borden committed the crime or to verify that she did not.' (Putnam 1992, 363; his italics). Admittedly, this special idealised form of verificationism presupposes that one can indeed have criteria for choosing the conditions that make an inquiry ideal. This is an important issue. But since it does not deal directly with the role of conceptual schemes, I will not examine it here. I will continue to develop my argument with the assumption that it is possible to formulate such criteria.

(3) When trying to safeguard, at least on the empirical level, the ontological dimension of the objects both of common sense, like tables and chairs, and of science, like the atoms which constitute the tables and chairs. Putnam accepts conceptual relativity. This means that: (a) the notion of an 'object' is essentially an inherently extendible one: we extend it for example when we speak of the strange 'objects' of quantum mechanics as objects, or again of Lezniewski's mereologocial sums as objects; (b) certain things are paradigmatically objects, for example tables and chairs, but other uses of the term 'object' are more or less optional; (c) consequently, apparently incompatible schemes may serve equally well to describe one or another state of affairs. The upshot is that the truth or falsity of 'There are five objects on my desk' is not scheme-independent. (Putnam 1992, 366-7).

This last point bring in the elusive term ‘conceptual scheme’. Is Putnam taking this to mean a point of view from where we see what is happening, or perhaps a particular way of organising experience? It seems, unfortunately, that he wants to allow two apparently incompatible situations. On the one hand, he wants to warrant occasional talk of incommensurability, where incommensurability means, as in Kuhn, 
that one language may have a set of sentences which cannot be translated into another language without remainder. He holds for example that for an internal realist there can be 'equally coherent but incompatible conceptual schemes which fit our experiential beliefs equally well' (Putnam 1981, 73). On the other hand however, especially when discussing values, Putnam gives the impression that he wants to avoid at all costs a situation where total relativism holds. He tries to do this, at one point, by holding our choice of values constant even though our notion of truth varies (Putnam 1981, 215).

The tension between these two opposing situations has made Evan Thompson suggest that the only way for Putnam to hold these two views together is for him to assume that there is in fact only one conceptual scheme for all humanity: 'if my construal of his argument is right, then Putnam must be committed to the idea that all persons share a conceptual scheme’ (Thompson 1991, 216-7). Another option, much more devastating for Putnam, is to abandon the whole idea of representation. In fact, it has been argued that conceptual schemes should have no significant role in any argument, or that the very idea of conceptual scheme is highly problematic (Davidson, 1980). What I propose however is that Putnam may still argue from within the representation-framework and offer a reasonably good account of what happens during interpretation and agreement between inquirers.

The main idea is to allow for a certain amount of flexibility when it comes to conceptualisation, but to insure a certain amount of 'same-ness' between inquirers so that the possibility of agreement and translatability is guaranteed. Consider what happens when two subjects, P and Q, whose conceptual schemes are different from each other, are trying to agree on certain propositions. Both $\mathrm{P}$ and $\mathrm{Q}$ have a cognitive faculty that enables them to evaluate propositions. Taking the hint from Putnam's proposal that 'the choice of a conceptual scheme is what cognitive rationality is all 
about' (Putnam 1981, 212), I want to suggest the following set-up: the scheme supplies the concepts and something else supplies their evaluation.

On this view, $\mathrm{P}$ and $\mathrm{Q}$ are capable of determining which propositions are belief-worthy and which are not. Such evaluation is the outcome of principles of justification designed to guide the inquirer in choosing his or her doxastic attitudes. One is therefore assuming that subjects like $\mathrm{P}$ and $\mathrm{Q}$ have a cognitive faculty with a certain way of operation. Following Goldman 1980, this operation may be represented as a function whose inputs are specific thoughts or propositions to be evaluated, and whose outputs are prescriptions to adopt this or that attitude — for example, believing the proposition to be true, or suspending judgement with respect to it, or having a particular subjective probability with respect to it.

Now, let me take a simple case of different conceptual schemes. If we compare a typical person of the 12th century with one of our time, we would say that they have different conceptual schemes: the former for example believes that the earth is flat, while the second does not. But as regards basic everyday practice, they both have the same doxastic attitude towards some basic propositions like, say, the proposition that 'one can plunge one's hand into water but one cannot do it into stone'. Generalising this, we see that, to ensure the possibility of P agreeing with $\mathrm{Q}$ for some basic propositions in spite of their different conceptual schemes, we are obliged to hold that the cognitive faculty of the one operates in a similar way to the cognitive faculty of the other for these propositions. Otherwise, we will have agreement only as a matter of chance, which is an option I am not considering.

This mechanism of cognition, call it $\mathrm{M}$, must therefore be common to both $\mathrm{P}$ and Q — and to all inquirers if we postulate the possibility of all inquirers agreeing on some basic propositions. This is what Putnam is taking to be the case for simple propositions involving paradigmatic objects. Without committing ourselves to saying 
exactly what constitutes $\mathrm{M}$, we can all the same ask the following question: what is the status of $\mathrm{M}$ ? Given the above discussion, is $\mathrm{M}$ necessarily part of a mindindependent reality in the sense employed by metaphysical realists? Surprisingly, it seems that the answer is yes: this is the price Putnam has to pay for refraining from the Davidsonian abandonment of conceptual schemes.

To show this, I will employ a reductio argument. First of all, it must be remarked that I am not considering here a priori truths. I will not be discussing the grounds for agreement about laws of thought, as in the case of agreement that the principle of non-contradiction holds. I will be limiting myself to agreement concerning a posteriori truths, like the basic proposition mentioned in the example above. With this proviso, the only way of considering $\mathrm{M}$ not mind-independent is to consider it mind-dependent: not by saying that belief-worthiness is simply determined capriciously by the individual, which will be naive, but by considering $\mathrm{M}$ the product of social customs and conventions, as is done sometimes when discussing meaning. In other words, $\mathrm{P}$ agrees with $\mathrm{Q}$ on the belief-worthiness of some basic propositions because their way of evaluating these propositions has been inherited from traditional values in society. Accordingly, $M$ is a set of rules which are fully dependent on society and which therefore are fully dependent on the mind of people constituting this society. On this view, principles of evaluation of beliefs are like paper money: they are of no value to an individual, but a group can create the fact that their pieces of paper have value to them. M would therefore be a set of evaluative rules for a particular group who conform to it and who hold that the explanation of why they do so, as opposed to conforming to any equally serviceable rival set, is that they each expect the others to do so, and each prefers to do so if the others do. This state of affairs is further complicated if all the members of the group have forgotten that it was an arbitrary decision on their part that made them consider pieces of paper as having value. After long usage, a group comes to consider its set of evaluative rules as fixed, canonical and binding, with the famous result that truths become illusions of 
which one has forgotten that they are illusions. $M$ is therefore the fruit of social custom in spite of the fact that it frequently disguises itself as mind-independent.

The problem with this however lies in the lack of standard of correctness. Suppose we say that $\mathrm{M}$ is equivalent to 'what most people consider the way to evaluate belief-worthiness'. This, taken as it is, is another proposition that demands evaluation. If we have recourse again to the formula 'what most people consider...' we will only shift the debate to another level without solving anything. An infinite regress will become unavoidable. Therefore no absolute standard is available on this line of argument. Society here is like a choir with neither conductor nor score. The only criterion at work is for members of the choir to try to silence those singers whose notes are discordant with the harmony being attempted by the majority. This situation does safeguard the idea of correctness, but only as applied to the individual. What about the idea of correctness as applied to the whole group? Consider the intention of the subjects P and Q. Presumably, when they reach agreement on basic propositions, they are not directly concerned with the assent or dissent of others. For them, this is only secondary with respect to what is the case. If they realise that their agreement has merely been the fruit of evaluation based on social pressure, we expect them to worry about the correctness of the proposition they agreed upon. Take our previous example again. Suppose someone attempts to explain why we all agree that 'one can plunge one's hand into water but not into stone' by saying that the agreement is the outcome of social conventions, somehow hidden in the past. This explanation will not satisfy us. And rightly so. The idea of considering $\mathrm{M}$ entirely dependent on social practice is an insufficient source of standards of correctness. It becomes clear that, from the global point of view, social practices do not fill the role demanded of them because they never lift propositions into a definitely normative dimension in which such propositions are susceptible of truth and falsity. 
If the above argument is correct, $\mathrm{M}$ is not a set of social rules. It must therefore be mind-independent in the same sense as that used by the metaphysical realist: whatever constitutes it is beyond conceptual schemes. We are hence entitled to say that, even in the context of internal realism, we have the possibility of dealing with something that is mind-independent, namely the mind-independent evaluative principles involved in agreeing to accept basic propositions. I do not think this will be a devastating blow to Putnam's views, even though it apparently goes against the first fundamental characteristic mentioned above. Our mechanism of cognition represents the non-plastic aspect of the mind. In other words it represents the traditional idea that all inquirers share something that may be called human nature - in Putnam's words, something that 'isn’t all that plastic.' (Putnam 1978, p. 56).

St. Edmund's College, Cambridge CB3 OBN, United Kingdom.

\section{References}

DAVIDSON, Donald, (1980) 'On the very idea of a conceptual scheme,' Inquiries into Truth and Interpretation, (Cambridge University Press).

Goldman, Alvin, (1980) 'The Internalist Conception of Justification,' Midwest Studies in Philosophy, vol. 5, P. French, Th. Uehling, H. Wettstein (eds.) (University of Minnesota Press: Minneapolis), pp. 27-51.

Putnam, Hilary, (1978) Meaning and the Moral Sciences, (Routledge and Kegan Paul: London).

----- , (1981) Reason, Truth and History, (Cambridge University Press).

----- , (1983) Philosophical Papers Volume 3: Realism and Reason, (Cambridge University Press).

----- , (1992), 'Replies,' Philosophical Topics, vol. 20(1), pp. 347-408.

Thompson, Evan, (1991) 'Is Internal Realism a Philosophy of Scheme and Content?' Metaphilosophy, vol. 22, No. 3, pp. 212-230. 
